Goldschmidt 2021 Abstract

https://doi.org/10.7185/gold2021.3128

\section{Rock/desert varnish geochemical characteristics: A study from Ladakh, India}

MR. AMRITPAL SINGH CHADDHA, MSC ${ }^{1,2}$, ANUPAM SHARMA $^{2}$, NARENDRA K. SINGH ${ }^{1}$ AND NIRAJ RAI ${ }^{2}$

${ }^{1}$ University of Lucknow

${ }^{2}$ Birbal Sahni Institute of Palaeosciences

Presenting Author: amrit.chemsingh@gmail.com

Rock/desert varnishes are thin coatings, mainly composed of $\mathrm{Fe}$ and $\mathrm{Mn}$ hydroxides and clay minerals and found most commonly in arid and semi-arid regions of the world. Rock varnish used earlier as petroglyphs has always been a keen area of interest for researchers; however, its origin is still debatable.

In the present study rock varnish samples have collected from the high altitude cold arid region of Ladakh in northwest India. The Rock varnishes are found on big boulders along riversides and from open barren areas too. The samples were chiselled-out from these big boulders and were analysed for chemical and genomic properties to validate certain recent mechanisms associated with the formation and chemical composition of rock varnishes. Our preliminary results display a contrast in morphology of varnish surfaces and the host rocks. The distribution of elements in the host rock (surface above which the varnish is present) and the varnish suggests the presence of elements such as $\mathrm{Mn}, \mathrm{Fe}, \mathrm{Si}, \mathrm{O}, \mathrm{Mg}, \mathrm{Na}, \mathrm{P}$, and $\mathrm{K}$ wherein, the concentration of $\mathrm{Mn}$ and $\mathrm{Fe}$ was relatively higher in the varnish layer, suggesting a prominent role of these two elements in the formation of the varnish layer. Additionally, 16sRNA genome analysis for the samples indicates the presence of Verrucosispora, Williamsia, Tsukamurella, Streptomyces and Streptosporangium genus as they all belong to the same phylum i.e., actinobacteria, which further support the microbial interaction in varnish formation. The stable isotopic values of $\delta^{13} \mathrm{C}\left(-20.4 \%\right.$ to $-25.1 \%$ ) and $\delta^{15} \mathrm{~N}(-1.2 \%$ to $4 \%$ ) suggest the biotic intervention and TOC/TN ratio $(<10)$ also indicates the role of microbial processes in the formation of rock varnish. The Raman spectroscopic analysis shows the presence of pyrolusite (a naturally occurring mineral comprised of $\mathrm{MnO}_{2}$ molecule), which also points towards the role of microbial mediated $\mathrm{Mn} / \mathrm{Fe}$ in rock coatings. These coating over the host rock surfaces protect the host rock against high UV irradiation, desiccation, and widely varying temperatures for years and keep them resistant against the weathering and erosional processes having wider implications.

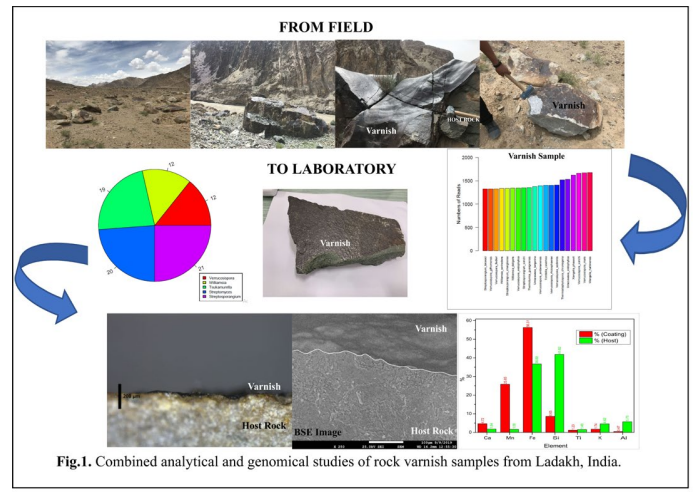

